University of Louisville

ThinkIR: The University of Louisville's Institutional Repository

\title{
Promoting diversity in the universal : rethinking universal design for learning.
}

Jill Sadowski

University of Louisville

Follow this and additional works at: https://ir.library.louisville.edu/honors

Part of the Bilingual, Multilingual, and Multicultural Education Commons, and the Women's Studies Commons

\section{Recommended Citation}

Sadowski, Jill, "Promoting diversity in the universal : rethinking universal design for learning." (2014). College of Arts \& Sciences Senior Honors Theses. Paper 55.

http://doi.org/10.18297/honors/55

This Senior Honors Thesis is brought to you for free and open access by the College of Arts \& Sciences at ThinkIR: The University of Louisville's Institutional Repository. It has been accepted for inclusion in College of Arts \& Sciences Senior Honors Theses by an authorized administrator of ThinkIR: The University of Louisville's Institutional Repository. This title appears here courtesy of the author, who has retained all other copyrights. For more information, please contact thinkir@louisville.edu. 
Promoting Diversity in the Universal:

Rethinking Universal Design for Learning

By:

Jill Sadowski

Submitted in partial fulfillment of the requirements

for Graduation (summa or magna) cum laude

University of Louisville

May 2014 


\section{Introduction}

The academic opportunity gap between black and Latino/a students and their white counterparts is well documented (Schott Foundation for Public Education, 2012, NCES, 2013). Students of color have higher dropout rates (NCES, 2013, Table 219.70), lower graduation rates (NCES, 2013, Table 125), and lower ACT scores (ACT National and State Scores, 2012) than white students. With such drastic inequality in academic achievement across racial lines, then it is safe to argue that the problem is, in part, related to how identity (racial, cultural background, ability, and class) is navigated in the classroom.

The policies in place to promote academic achievement in public schools (such as the newly implemented Common Core) do not take into consideration the diverse needs of all the students in the classroom. However there is a framework that is already doing this-- Universal Design for Learning (UDL). Universal Design for Learning is a curriculum based framework that aims to ensure that students are able to access their education. The neuroscience based framework is built around the concept of multiple means-- specifically multiple means of representation, action and expression, and engagement (CAST, 2011). UDL was intended to make classrooms accessible for disabled students but has since been recognized as a tool for other identities as well (Chita-Tegmark, Gravel, Serpa, Domings, \& Rose, 2011-12). Accessibility, in this case, refers to if a student is able to, in the most general way, access their education. Although the term is specifically used in the discourse surrounding disability access, in this text I am using an expanded, more generalized term. Further, accessibility in this context denotes engagement-- is a student able to meaningfully connect with their education? -- education is accessible when it promotes engagement.

In this paper, I draw from research in sociology, education, and neuroscience to explore how 
Universal Design for Learning is an effective tool for ensuring an accessible education across lines of diverse identities. Specifically I will focus on how UDL can be applied to make education more accessible for students of color, focusing largely on black and Latino/a students. Although I am arguing for the use of UDL, I also present a critique of the framework. In order for UDL to be truly effective, it must be expanded. I argue for an expanded definition of the UDL principle of multiple means, proposing that the principle be expanded to include multiple identities in the classroom. My aim is to understand how who is represented in the classroom affects the accessibility of the information for the individual students. Thus, if UDL is to be useful as an accessibility tool, the framework's reliance on diversity must be expanded to include the representation of different identities in the classroom. In sum, my contribution in this paper is to synthesize research from sociology, education, and neuroscience on UDL and identity development in order to better understand and critique the effectiveness of UDL.

My critique of UDL questions what issues may arise in implemented UDL in classrooms. In this text I will specifically focus on the identities of both students and teachers, with a more heightened focus on the identity of the teacher. I will be examining UDL with the intent to critique and begin the discussion on representation in the context of UDL-- I will not be outlining specific policy or programming changes.

I focus on K-12 public education in the United States (not including charter schools), and concentrate on how racial identities in the classroom affect students' ability to access education. I will specifically examine how segregated classrooms and the dominance of white women teachers in the field play a role in students' educational accessibility. I suggest that part of the solution to the education system, as UDL proposes, is to focus on the essential part that diversity plays in educational accessibility. Universal Design for Learning argues extensively for flexibility and multiplicity in representation, action and expression, and engagement. Thus, it is natural to expand the emphasis on multiplicity and diversity to who is represented in the classroom. I am specifically proposing that 
student's identities should be reflected in the identities around them in order to create a more accessible and inclusive space.

I will first examine the current state of education in the U.S., followed by an explanation of the theories and research behind Universal Design for Learning. From there I will explore UDL as a tool for diverse learners, and then offer a critique of the framework. In the second half of my paper I aim to explore how representation affects learning and connect that back to a critique of UDL as a comprehensive tool.

Another concept that is important to note is the use of the term diversity. In this paper I use the term "racial diversity" to denote the presence of white, black, and Latino/a students. Racial identity is also heavily linked to issues of culture, language, gender, and class. These latter identities are not the focus of this paper, but will be mentioned when they appear in the literatures reviewed below. Also, although I will be using the term Latino/a, many of the works I cite use Hispanic, so both terms will be used interchangeably. Further, in terms of the field of educational research terms such as multicultural or culturally diverse are used. When using the term "culture," I am specifically referring to the customs, language, and way of life of different social groups.

\section{Current Trends in Public Education}

In order to contextualize Universal Design for Learning, we must first explore the current state of the United States public education system. According to the U.S. Census Bureau, as of July 1, 2011 more than fifty percent of the nation's population under the age of one were non-white minorities (2012, May 17). America is not only becoming less white, but the demographics of poverty are also shifting. According to Addy, Egelhardt, and Skiner (2013), from 2006 to 2011 "the overall number of children of all ages increased by less than one percent while the numbers who were low-income and poor increased by 13 percent and 23 percent, respectively." (p. 2). There is a shift occurring in the lived 
experiences of American children and that is reflected in the public school system.

One demographic shift that is occurring in public schools is along racial lines. Table 1

illustrates the race of the school-age population over time; the percentages refer to the total school-age population:

Table 1

School-Age-Population by Race

\begin{tabular}{|l|l|l|}
\hline Race & School-Age Population 1995 & School Age-Population 2010 \\
\hline White-Non-Hispanic & $64.7 \%$ & $52.4 \%$ \\
\hline Black-Non-Hispanic & $16.8 \%$ & $16.0 \%$ \\
\hline Hispanic & $13.6 \%$ & $23.1 \%$ \\
\hline
\end{tabular}

Note: from (NCES, 2013, Table 44)

It is important to note that the demographic shift along racial lines currently at work in public schools varies by location (Taylor \& Whittaker, 2003). Thus, this shift is more evident in some places compared to others-- more diverse in urban areas versus rural, and there are higher concentrations of certain populations in certain areas (more Latino/a students in the Southwest). Further, students in poverty are also on the rise in American schools. The National Center for Education Statistics (2013, Table 25) documented in 1990 that 17 percent of children were in poverty and according to their latest data available, that number rose to 20.7 percent in 2011. The school system is also changing as students are increasingly using English as their second language. Students in English Language Learning programs rose from 8.7 percent for the $2002-2003$ school year to 9.8 percent for the $2010-2011$ school year (NCES, 2013, Table 47). Thus, the demographics of students in American classrooms are changing significantly. 
Despite the fact that American K-12 students are becoming less white, more likely to be in poverty, and more likely to use English as their second language, the employees of the schools do not reflect the changing population. The latest data from the School and Staffing Survey (2007-2008) shows that of the $3,898,420$ public school teachers, $239,460(6.14 \%)$ are black, $240,310(6.16 \%)$ are Hispanic, and 2,829,150 (72.57\%) are white. Not only are the public school teachers overwhelming white, they are also overwhelmingly female-- 75.9 percent (School and Staffing Survey, 2007-2008). The teaching profession, specifically public education, is a field dominated by white females.

However, the dominance of white women in the teaching field may be slowly changing. Flores (2011) suggests a "browning of teachers" (p. 314), in which more Latina women are entering the teaching profession, especially in California. In fact, Hispanic individuals are the fastest growing nonwhite group entering the field (Feistritzer, 2011.) Although this change is promising, it is happening slowly, only in certain areas, and white women are still the dominant identity in the education field.

The racial, ethnic, and language demographics of the students in public education are shifting because of the changing shift in the United States population. The reality of who is in a given classroom is shifting due to changing policies and trends in the greater society. With the implementation of the Education for All Handicapped Children Act of 1975, the U.S. public school system began using the Least Restrictive Environment (LRE) policy. LRE "is the concept of educating children with disabilities along with children who are not disabled to the maximum extent appropriate, ideally in the regular classroom" (Rothstein, 2000, p. 107). The LRE introduces the concept of mainstreaming disabled students- placing them in nonspecial education classrooms. The passage of the Individuals with Disabilities Education Act (IDEA) in 1990 and various amendments along the way have shaped the public schools interest in creating and maintaining the least restrictive environment. Thus students who may have previously been segregated into special education classes now must be placed in the least restrictive environment. In other words, 
the students are mainstreamed into the general classrooms. This has created a great shift in who is present in a given classroom or even a given school. For example, in 1975 approximately 20,000 deaf and hard of hearing students were enrolled in state residential schools for the deaf (Schildroth \& Horton, 1994). According to IDEA Data collected in 2011, out of the 69,312 students classified as "hearing impaired", only 2,366 were enrolled in residential schools. The demographics of the American classroom are shifting- how are we keeping up? It is essential to examine the policies and programs that are in place that are directly tied to the diverse demographics in public schools.

\section{Reproducing Inequality}

When I talk about racial inequality in schools, I am specifically referring to academic opportunity gaps across racial lines. H Richard Milner (2010) argues that we should refocus our understanding of "academic achievement gap" to "opportunity gap." Opportunity gap better focuses the discussion on the problem: the unequal opportunities available to students (access to resources, curriculum, and teachers) and how the access to opportunities is what affects academic outcomes. In this portion of the text, I aim to explore gaps in achievement at their very basic form, for example: graduation rates, reading and math scores, and ACT scores. This discussion will be situated in a larger dialogue on policies and practices that affect the opportunity gap for students across racial lines.

First, looking at the National Assessment of Educational Progress (NAEP) scores for both math and reading, gives insight into how kids are performing in schools (see Table 2, page 7). The data documents the educational gap across racial lines for students in the areas of math and reading. Across the board, students of color are trailing behind. We see this trend continue when we examine graduation and dropout rates. Although it is difficult to predict graduation rates, the Average Freshman Graduation Rate (AFGR) serves as an estimate of the percentages of students who will graduate from high school within four years. For the 2009-2010 school year, the graduation rates are as follows: White-Non-Hispanic- 83\%, Black-Non-Hispanic- 66.1\%, and Hispanic students percent of graduation 
stands at 71.4\% (NCES, 2013, Table 125). Again, we see white students excelling in contrast to students of color. We see the same trend in dropout rates of students. From 2012 the dropout rate rates of White-Non-Hispanic are at 4.3\%, Black-Non-Hispanic students are 7.5\%, and Hispanic students are 12.7\% (NCES, 2013, Table 219.70). Graduation rates and dropout rates reflect an academic opportunity gap across racial lines.

Table 2

NAEP Reading and Math Scores by Race of Student

\begin{tabular}{|c|c|c|c|c|c|c|}
\hline \multirow[t]{2}{*}{ Race } & \multicolumn{3}{|c|}{ NAEP Reading Scale Score (2009) } & \multicolumn{3}{|c|}{ NAEP Mathematics Scale Score (2009) } \\
\hline & $\begin{array}{l}4^{\text {th }} \text { grade, all } \\
\text { students }\end{array}$ & $\begin{array}{l}8^{\text {th }} \text { grade, all } \\
\text { students }\end{array}$ & $\begin{array}{l}12^{\text {th }} \text { grade, all } \\
\text { students }\end{array}$ & $\begin{array}{l}4^{\text {th }} \text { grade, all } \\
\text { students }\end{array}$ & $\begin{array}{l}8^{\text {th }} \text { grade, all } \\
\text { students }\end{array}$ & $\begin{array}{l}12^{\text {th }} \text { grade, all } \\
\text { students }\end{array}$ \\
\hline $\begin{array}{l}\text { White- } \\
\text { Non- } \\
\text { Hispanic }\end{array}$ & 230 & 273 & 296 & 248 & 293 & 161 \\
\hline $\begin{array}{l}\text { Black- } \\
\text { Non- } \\
\text { Hispanic }\end{array}$ & 205 & 246 & 269 & 222 & 261 & 131 \\
\hline Hispanic & 205 & 249 & 274 & 227 & 266 & 138 \\
\hline
\end{tabular}

Note: from (NCES, 2013, Table 142) and (NCES, 2013, Table 160)

As students' progress through the public education system we see certain students struggle while others continue to succeed. It is possible to see this as students attempt to transition out of high 
school and into college. Unfortunately, ACT scores illustrate the same racial disparities. Out of a score range of 1-36, White individuals averaged a score of 22.4, African American individuals averaged a score of 17.0, and Hispanic individuals averaged a score of 18.9 (ACT National and State Scores, 2012). Further, The Condition of College \& Career Readiness 2012 found that while $38 \%$ of white high school graduates met ACT college readiness benchmarks in all four subjects (math, English, reading, and science) only $13 \%$ of Hispanic graduates and 5\% of African American graduates did (ACT, 2012, p. 5). The educational gap between white students and black and Latino/a students are well documented. The question then becomes, why students of color do not fare as well as white student.

To explain the academic opportunity gap among racial/ethnic groups, Barton and Coley (2009) explore school factors, such as: curriculum rigor, teacher preparation, teacher experience, teacher absence and turnover, class size, parent involvement, access to resources, and environmental factors (health, poverty, school safety) that affect school opportunity gaps (p.3). The schools that scored lower on these criteria are more likely to serve more students of color and low-income students; thus the gaps in academic achievement reflect differences in educational quality (Barton and Coley, 2009). It is on this note that we take a closer look at some of these factors.

With the 1954 Brown v Board of Education came the end of segregation in public education de jure and with the 1970 Swann v Charlotte-Mecklenburg Board of Education Supreme Court case, came the start of integration through busing students to different schools. Almost sixty years after Brown v. Board of Education, the public education system remains segregated across racial and class lines (Orfield \& Eaton, 1996). The reality of resegregation is due to the same procedures that were intended to desegregate classrooms: laws, court rulings, and policies. For example, the 1990 ruling of Board of Education of Oklahoma City halted busing and reinstated neighborhood schools, effectively segregating the schools (Tatum, 2007). Reinstating neighborhood schools is problematic, because 
neighborhoods remain quite racially segregated due to white flight and the concentration of minorities in poor urban areas (Wilson, 1987). Thus, racial segregation typically intersects with class segregation, such that disproportionately minority neighborhoods have higher poverty rates and fewer resources. For example, 90 percent of highly segregated Black and Latino schools also have high rates of poor students while most schools dominated by white students are majority middle class (Boger \& Orfield, 2005). Schools continue to be racially segregated sixty years after Brown v. Board of Education, and in turn resources are allocated across racial lines. As most schools operate on budgets funded by residents' tax bases, schools are funded unequally. Lower-income schools, often populated with more students of color, typically have fewer resources compared to schools in other areas.

It is also important to consider who is in the classroom, and who is teaching the class as well. Freeman, Scafidi, and Sjoquist found that the higher the population of minority students in a school, the more likely that the white teachers lack experience, lack advanced degrees, and are more likely to leave the school after a short period of time (2005). Segregated schools often lack experienced teachers and more importantly, teachers who are and remain attached to the community they are serving. Further, how teachers feel about their schools affects learning outcomes. Ostroff (1992) found that there is a correlation between teacher satisfaction with their job and the percentage of students on free lunch-- the higher the percentage of such students, the less satisfied the teachers are. The effects of this are far reaching; Ostroff (1992) reports that teacher satisfaction can predict student's academic achievement: attendance, dropout rates, and disciplinary measures.

With the implementation of tracking students by academic ability it is possible that even in schools that have a diverse student body, the classrooms will be segregated by race. White students are well represented in gifted and talented and advanced placement classes while students of color are overrepresented in rates of dropouts, suspensions, and special education classes (Schott Foundation for Public Education, 2012). So even under the guise of a desegregated school, the classrooms themselves 
are often racially segregated. Ability grouping begins early; for example, elementary school black students (especially boys) are disproportionately placed into special education classrooms while their white counterparts are more often placed into gifted education classrooms (Mickelson, 2005). The racialized tracking system is a policy that resegregates classrooms, limits students access to education and opportunities, and creates a racialized understanding of who is smart and who isn't.

The implications of segregated classrooms and failing policies are far reaching. With the implementation of zero tolerance policies in the late 1980s during an uptick in juvenile crime (Skiba, 2004) the school discipline system witnessed a great shift. According to Skiba (2004), zero tolerance policies punish all acts more severely across the board, resulting in the increase in the duration and amount of suspensions, expulsions, and other disciplinary procedures. Although zero tolerance policies are intended to make schools safer, there are drastic side effects. Schools with high rates of suspension tend to have lower academic achievement, higher dropout rates, and an overall uninviting school climate (Skiba, 2004). Zero tolerance policies are not racially unbiased. Black and Latino/a students are more likely to be suspended, expelled, or even arrested for their conduct compared to their white counterparts (Advancement Project, 2005, Skiba et al, 2011). Skiba et al (2011) attributes this overabundance of black and brown bodies in disciplinary measures to several factors, including school settings, rates of poverty, mismatch of teachers' perceptions of normative behavior and students' performance, and racial stereotyping (p. 86). Zero-tolerance policies create and maintain schools that are segregated across racial lines.

Policies that filter students of color into disciplinary measures also effectively fuel the schoolto-prison pipeline. The school-to-prison pipeline is a system maintained by education and public policies that funnel students out of school and into the juvenile or criminal justice system (Archer, 2009, p. 868). The pipeline is facilitated through school policies such as excessive disciplinary measures and zero-tolerance policies that directly and indirectly put kids on a track that often ends in the prison 
system. The school to prison pipeline is also racialized-- black students are more likely to be suspended, expelled, or arrested for their conduct compared to their white counterparts (Advancement Project, 2005). Further, United States prisons are disproportionately filled with Black and Hispanic inmates as well as inmates with mental illness (Gostin, Vanchieri, Pope, Institute of Medicine (U.S.)., \& Institute of Medicine, 2007). As the U.S. demographics continue to shift and the opportunity gap across racial lines is maintaining or worsening, it is important to look into what new policies schools are implementing to facilitate effective learning.

Currently, public schools across the country are implementing are the Common Core Standards. The standards are meant to overhaul and re-frame the failing education system, so that students leave high schools with the skills needed in society. The overarching goal is to clarify expectations in the two areas of English and math through the use of new textbooks and materials as well as new assessment systems. The Common Core in an attempt to end the confusing and inconsistent academic goals in schools across the nation-- however, some argue that thus far it is only making education more confusing (Bertin, 2014). Further, the standards are noble but not necessarily accessible- they will assist already successful students but they are not designed to address all the needs of failing, disabled, and diverse students. The Common Core Standards promote the use of a singular standard for all students to meet without outlining how to make the standards accessible to students who may be struggling. Granted, the Common Core is more straightforward than our previous policies (or lack thereof); it still does not address the needs of struggling students. It is not a complete solution, so it is important to look into what other frameworks may better facilitate learning.

\section{Universal Design for Learning}

The Center for Applied Special Technology (CAST) was founded in 1984 with the mission of creating accessible education through technology for people with disabilities. Universal Design for Learning is a framework for curriculum development that intentionally creates a flexible and accessible 
space for education across lines of ability (Rose and Meyer, 2002). UDL focuses on how to engage different types of learners, specifically those who have disabilities or are gifted and talented. Instead of having a pre-determined, mass mandated curricula and then changing it when a disabled student enters the room, UDL proponents argue for a restructuring of educational environments to be accessible and varied from the beginning. Three primary principles based in neuroscience research guide UDL: multiple means of representation (diversity in how the material is presented), multiple means of action and expression (diversity in how the student can express what they know), and multiple means of engagement (diversity in motivating students) (Rose and Meyer, 2002). Universal Design for Learning directly addresses diversity in the classroom through the use of diverse teaching methods. Unlike the Common Core, UDL is built to be inclusive from the beginning, instead of an afterthought. The framework is an essential tool in creating an accessible and inclusive classroom. First I want to explore the neuroscience research behind Universal Design and then I will explore the fundamental guidelines more in depth.

\section{Neuroscience Research}

Universal Design for Learning is based on how networks in the brain interact with the learning environment. The brain itself is made up of many specialized networks, and UDL relies on three primary networks that are all equally essential to learning. Rose and Meyer (2002) “...identify the networks by terms that reflect their functions: the recognition, strategic, and affective networks." (p. 12). Further, the researchers identify two characteristics for learning: that processing is lateral (simultaneous processing) and that processing is hierarchical. Hierarchical processing breaks down into two subsets: bottom-up and top-down recognition processing. Bottom-up processing is the process of receiving sensory information at a low context, for example, vision: "As visual sensory information we take in through our eyes departs from our retinas, it travels up through an increasingly complex hierarchical network, eventually reaching the visual cortex." (Rose and Meyer, 2002, p. 16). In contrast, 
top-down processing utilizes background information, context, patterns, etc. in order to make sense of what we are seeing, hearing, etc. All three networks are organized as both hierarchal (bottom-up and top-down) as well as lateral processes. Both the three networks and the two characteristics for learning compose the foundation of UDL.

Recognition networks are specialized to identify and assign meaning to patterns, concepts, and ideas (Rose and Meyer, 2002). More fundamentally, it is through the recognition networks that we can understand sound, recognize faces or letters, make sense of concepts or patterns, etc. Recognition networks are distributed throughout the brain and differ based on what sensory mechanism is being utilized. Recognition networks also vary profoundly from person to person.

Strategic networks are specialized to facilitate and monitor both mental and motor abilities. The strategic network houses our actions, skills, planning, etc. Variations in the strategic networks are wide ranging and influence how well an individual is able to execute a given action. Although strategic networks are composed of both bottom-up and top-down recognition processing, individual variations in the degree of bottom-up or top-down affect how an individual is able to learn a new skill (Rose and Meyer, 2002, p. 27). The degree of processing is directly related to the reality that some individuals learn better from seeing the skill performed while others prefer to read about the skill or prefer to approach it hands on.

Finally, affective networks are specialized to recognize patterns and assign meaning, significance, and value to them. Affective networks are emotionally based and are tied directly to how individuals' previous experience affects their ability to perform today. This network deals with issues of anxiety and other mental health issues and is essential for learning but is given the least recognition out of the three processes (Rose and Meyer, 2002, p. 35).

Rose and Meyer (2002) emphasize that the three networks work together, take for an example a 
birthday card for a friend:

Through recognition networks, we understand the concept of a birthday and identify the card, the pen, our hands as we write, and our signature. Through strategic networks, we set our goal of signing the card, form a plan for picking up the pen and moving it to produce our signature, monitor our progress, and make small course corrections, such as reducing the size of the letters if we begin to run out of space. Affective networks connect us to our feelings for our friend, motivate us to sign the card, and keep us on task. (p.13)

The neuroscience research grounds Universal Design for Learning in scientific empirical data. It is through the research surrounding recognition networks that the UDL establishes their curriculum based framework.

\section{Fundamental Guidelines}

The UDL framework is built upon the essential nature of flexibility in education. As we address diverse schools and how to promote accessible and inclusive education, UDL has answers. First and foremost it is centered on flexibility as a built-in entity in educational curriculum. Most curriculums (including the Common Core Standards) outline one way to take a test, make a presentation, or produce a paper. UDL directly opposes non-flexible curricula. Second, UDL focuses on supporting improved access to the process of learning as well as access to information in the classroom environment for all students, regardless of ability. (Rose and Meyer, 2002, p. 72). The framework is curriculum centered and incorporates and advocates for the use of technology in the classroom. There are three main principles of UDL that are directly based off of the three network processes. Overall the framework offers one essential recommendation: "to provide students with a wide variety of options" (Rose and Meyer, 2002, p. 72). The "options" in learning are tied to how a student is able to receive information, 
engage with it, and respond to it. Flexibility and diverse options are key components to UDL.

The three principles are as follows: provide multiple means of representation, provide multiple means of action and expression, and provide multiple means of engagement (CAST, 2011). UDL stresses the essential need for multiplicity in the process of learning and that is apparent in all three principles. The first principle directly responds to the recognition networks. CAST (2011) acknowledges that individuals vary in how they take in and comprehend information: based on ability status (deaf, blind, dyslexia, etc.), language status, cultural identity, etc. Some students learn better through auditory or visual means, while some prefer reading text. Thus, multiple means of representation are important to better facilitate students access to information. The principle of representation is broken down into three key guidelines: provide options for perception (visual, auditory, touch), provide options for language, mathematical expressions, and symbols (promote clarity and comprehension across mediums), and provide options for comprehension (providing scaffolds-a temporary tool to assist learning- think of training wheels!) (CAST, 2011). Providing multiple means of representation improves the facilitation of learning-- students can access information through the medium of representation that works best for them.

The second principle is providing multiple means of action and expression and it is tied to the strategic network. The way a student can respond to the information presented is directly dependent on the student's abilities. If a student has significant movement impairments, a strategic and organizational disability or a student who speaks a different language, that would affect their ability to participate in a given class assignment or activity (CAST, 2011). No one action or expression is able to be executed by every student-- thus UDL argues for the implementation of multiple options for action and expression. There are three guidelines for the second UDL principle: provide options for physical action (accessible tools and materials, vary response methods), provide options for expression and communication (multiple means of communication, construction, and composition), provide options for executive 
functions (facilitate student's ability to set goals, plan, and monitor own progress) (CAST, 2011). The principle of multiple means of action and expression is directly tied to the strategic network and allows students to learn in the way that works best for them.

The final principle deals with the affective networks of the brain, with the goal of providing multiple means of engagement. This principle deals with emotions and the reasons a student would be motivated to learn and engage with the classroom materials. Engagement is directly related to the topics, routines, and project and assignment structure of the class. There are three guidelines for principle of engagement: provide options for recruiting interest (optimize choice, autonomy, relevance and minimize threats and distractions), provide options for sustaining effort and persistence (fosters goals, collaboration, and communication and varies demands), and provide options for self-regulation (facilitate personal motivation, coping skills, and self-reflection) (CAST, 2011). The principle of engagement is an essential yet often ignored principle of the UDL framework, and it relies heavily on emotions, personal interests, and mental health.

\section{Application in Public Education}

The UDL framework is a relatively new endeavor that is quickly gaining ground (and in turn, recognition), throughout the United States. School systems, districts, teacher professional development, educational policies, and individual schools are referencing and incorporating UDL into their practices (Sopko, 2009). In the 2008 re-authorization of the Higher Education Act (HEA) known as the Higher Education Opportunity Act (HEOA), UDL is included (HEOA, 2008):

UNIVERSAL DESIGN FOR LEARNING. - The term 'universal design for learning' means a scientifically valid framework for guiding education practice that-

(A) provides flexibility in the ways information is presented, in the ways 
students respond or demonstrate knowledge and skills, and in the ways students are engaged; and

(B) reduces barriers in instruction, provides appropriate accommodations, supports, and challenges, and maintains high achievement expectations for all students, including students with disabilities and students who are limited English proficient [HEOA, P.L., 110-315, § 103 (a) (24)]

Universal Design for Learning- is not specifically embedded in federal K-12 legislation (including No Child Left Behind (NCLB) and Individuals with Disabilities Education Act (IDEA)) but it is referenced in IDEA, specifically for the Assistive Technology Act (Sopko, 2009). The UDL framework is gradually gaining ground in the formal policies and procedures of the United States Education System.

In terms of the new Common Core Standards, CAST (2010) released "Recommendations for the Common Core Standards" in which they argue that the standards themselves may create barriers to in the classroom. Although the standards refer to UDL, they are not based fundamentally on the principles of UDL. The UDL framework continues to gain ground and in turn, recognition throughout the school system. However, there is a long way to go.

\section{UDL in the Real World}

Universal Design for Learning is a relatively new framework, and the research around the framework centers on application in classrooms and teacher training. As the research base is expanding over time, the evidence on the impact of UDL on a learning environment remains limited. However, a few studies explore the implementation of UDL in classrooms. For example, Kotering, McClannon, \& Braziel (2008) conducted research on student perceptions of UDL interventions in Algebra and Biology high school courses. The study focuses on a comparison between mainstreamed disabled students and 
general education classes in two different high schools. The authors found that students reported high rates of perceived engagement with UDL practices compared to their classes with no UDL intervention. Further, both groups agreed in wanting their teachers to incorporate more UDL into their teaching practices. The authors point out that although there are limitations to this study, Universal Design for Learning can facilitate engaging learning environments for both disabled and non-disabled students.

One intensive study of UDL implementation for 867 students in grades 5-12 focuses on the students' perceptions of the learning environment, specifically if their grade level or gender of the teacher affects the learning environment. Abell, Jung \& Taylor (2011) found that high school students were most likely to report high scores for their classrooms that implemented UDL in terms of both personalization and participation. Keeping in mind that according to Simmons and Blyth (1987), once students reach early adolescence they often disengage with their education, seeing it as less important and themselves as less academically capable, Abell et al.'s study makes a particularly strong case in favor of UDL usage. Further, students reported a more personalized learning environment with a female teacher. Although some may interpret this finding as evidence in favor of maintaining the female domination of the teaching profession, I would be cautious in asserting so. This finding calls for further research into why female teachers are able to create more personalized classrooms in comparison to male teachers.

Although we are concerned with UDL implementation in K-12 public education, it is pertinent to mention Smith's (2012) research into UDL in a college classroom. The study was limited to one classroom but the findings were positive. Both the faculty member and the students in the graduate course found UDL implementation to be meaningful in their education. Specifically, Smith found that using UDL in designing courses resulted in more clearly-defined goals for the course and greater student engagement and interest in the course.

Concerning the practicality of UDL implementation, Spooner, Baker, Harris, Ahlgrim-Delzell, 
\& Browder (2007) findings suggest that even a simple introduction to UDL practices can help teachers design more accessible lessons. In sum, while the research on the implementation of UDL into classrooms is in its beginning stages, the early results are promising and strongly suggest that UDL is able to improve the classroom environment and promote learning.

\section{Universal Design for Learning as a Multicultural Tool}

Universal Design for Learning is a framework that was specifically designed as a way to make education accessible across lines of disability status. The researchers at CAST also briefly mention English language learners and cultural groups as demographics that would benefit from UDL (Rose \& Meyer, 2002). Researchers are beginning to recognize UDL as a useful tool across diverse cultural learners (Bowe, (2000), Ayala, Brace, \& Stahl (2012), Blizzard \& Foster (2007)) Although UDL is grounded with disabled learners in mind, its application as a tool for diverse learners (on the basis of race, ethnicity, or cultural background) is acknowledged in most works. The research surrounding the intersection of UDL and diverse identities is not as in-depth as research around disability. Further, the information that addresses multicultural education and UDL does not explore how cultural background and racial identity affect learning. There are only a few works that acknowledge neuroscience and directly connect UDL to cultural identity.

One such work, by Chita-Tegmark, Gravel, Serpa, Domings, \& Rose (2011-12), proposes that UDL can be extended to benefit diverse learners. They specifically utilize the term culturally diverse students instead of multicultural learners. The authors assert that "most of the focus of UDL has been on learner variability attributable to what is referred to as disability, with less attention to learner variability attributable to experience or culture.” (p. 17). In other words, UDL as a framework to support different cultural identities has yet to be explored in-depth. The authors specifically focus on techniques that can be used in the classroom that would reflect the cultural realities of the students, such as creating cultural bridges or scaffolds in order to facilitate comprehension. As UDL is a 
curriculum based framework, this piece focuses on how the structure of a curriculum alters students' ability to access information across cultures. The authors argue that cultural identity and difference are sources of brain difference in learning. In other words, a student's cultural background (including but not limited to: language, cultural understandings of time or direct/in-direct communication) affects how a student is able to relate, engage, and understand their education. The article is grounded in research around how experiences and culture "inform all aspects of learning, from the high-level reasoning skills to perceptual habits.” (p. 17). The short article is a powerful beginning to research around UDL and culture. The authors position issues of identity difference as a problem embedded in (and solved by) the curriculum. I argue instead that issues of accessibility along lines of difference extend beyond the curriculum. The framework of multiple means proposed by UDL must be expanded to include the identities in the room in order to be an effective tool.

Unfortunately, the above stated work is the only major text that begins to hash out exactly how UDL can be a tool for culturally diverse learners and how it can be applied. As the research surrounding the intersection of UDL and culturally diverse students is less extensive, the implementation of UDL in the classroom through policies, laws, and procedures is mostly focused around disabled students.

\section{Critique of UDL}

Although I support, utilize, and advocate for Universal Design for Learning, I cannot accept it without acknowledging its limitations and issues. There is very little active critique of UDL within the field of study, which is problematic in and of itself. One continuous debate in the research concerns how, and in what ways UDL (a technology based framework) can be applied in low tech settings (Rose, Gravel, \& Domings, 2012). However, that is the main critique of UDL that scholars provide.

As previously explored, UDL is now linked to issues of accessibility for learners across lines of 
race, ethnicity, and so on. Thus, it is important to examine how issues of class, race, gender, and language are tied to UDL practices. For example, UDL researchers have a copious amount of reading materials in order to promote and attract educators to UDL. The literature is loaded with situational success stories. One such work by Coyne et al. (2009) shares observations from classrooms currently implementing UDL:

In a middle school science class, a teacher created a new assignment for her human anatomy unit: building a working joint. The teacher posted this assignment on the school website and invited parents to work with their students in fulfilling it. The resulting models- made from PVC pipes, rubber bands, bungee cords, door hinges, and other household items - were put on display in the school for the community to view. Building the joint and seeing multiple examples of the completed project helped students better understand this complex anatomical concept. As an added bonus, parents got involved in the assignment, too, and came to school to view the other models. (P.8-9)

The literature is flooded with stories just like this and they raise the question: what issues of accessibility are the researchers missing? We have to think about additional issues of accessibility-- for example, is a student able to access a computer after school? In 2011 the U.S. had $20.7 \%$ of children living in poverty (The National Center for Education Statistics, 2013b). Further, what types of parents will be off work to assist? Women with children under the age of 18 make up $65 \%$ of the female workforce, while fathers make up 86.2\% of the male workforce (U.S Bureau of Labor Statistics, 2012). In $2014,5.1 \%$ of the female workforce was working multiple jobs, while $4.2 \%$ of the male workforce had multiple jobs (U.S. Bureau of Labor Statistics, 2012). After the project is finished the parents are invited to come to the school to view the projects. This once again goes back to what types of parents are able to attend activities at school. Teachers and staff view lack of parent involvement as a lack of 
motivation, cooperation, lack of concern for child's education, and education in general (Lopez, 2001) although there may be other issues at work (such as health, work, or caring for other children). Peña (2000) found that parents' involvement in their child's education was influenced by the parent's cultural beliefs and attitudes, the school's attitude, parent's educational obtainment, and language, among other factors. It is unclear how UDL could be used to address issues like parent involvement, parent-teacher relationships, and access to technology, all of which clearly influence student's engagement in their education. UDL as currently structured is positioned as a tool to make classrooms innately accessible across lines of identity. However, it is harmful to view UDL as an all-inclusive tool. It is not inclusive to other aspects that affect a student's ability to access their education, whether that be economic resources outside of the school or being able to negotiate parent-teacher relationships in the context of education.

Another problematic issue is the formatting of UDL as a tool to end all tools, as if proper implementation of UDL will eradicate most, if not all, issues of inequality in the school. Dolmage (2008) outlines a critique: “many object that (Universal Design as) 'just good teaching' could lead to the same old neglect of and the same old invisibility for the disabled students."(p. 26). Dolmage recognizes an important issue with UDL: if UDL is implemented properly it could actually further marginalize the disabled students by not acknowledging their existence. By creating a space that is accessible from the beginning, it is possible to ignore student's specific identities as the space is already inclusive. The individual identities of the students still need to be recognized and validated no matter how accessible the space is. I now turn to identity development research to explore what role representation plays in education. In doing so, I will explore the ways in which an expanded understanding of UDL principles could, or could not, help counteract current inequalities in public education based on students' racial identities.

\section{Blue Eyes, Brown Eyes}


The day after the assassination of Martin Luther King Jr., April $5^{\text {th }}, 1968$ a school teacher in a small, almost entirely white town in Iowa decided she wanted to do something different. Over the next two days Jane Elliott conducted the now infamous Blue Eyes Brown Eyes experiment, documented in The Eye of the Storm (1971). On the first day blue eyed children were given special privileges such as sitting in the front of the class, or receiving seconds at lunch. At the same time the brown eyed students were told in one way or another that they were stupid, could not remember basic instructions, or that they behaved badly based solely on their eye color. The second day the roles were switched: brown eyed students were given preferential treatment. Some of these third graders had never even met a black person in their white town, but through Elliot's activity they were able to see how oppression based on identities operates.

Elliott encouraged the privileged student of the day to not interact with the discriminated group. Her constant reminders of who was less than, who was incapable, who was stupid and who was smart began to wear on the children. You can see it in their facial expressions, their silence, their meek body posturing. The discriminated group of students began to function differently in class. Most telling, the students began to respond differently to material presented to them, based on their identity. The perceived superior identity changed the students' ability to respond to material correctly and timely. For example, a phonics card pack activity yielded drastically different results depending on the day. On the first day where brown eyes were seen as stupid the group took five and a half minutes sorting through the deck, while the next day when they were privileged, they were able to complete the activity in only two and half minutes. Similar results occurred with the blue eyed students. The way they were treated in the classroom by their teacher and their peers affected their ability to succeed in the classroom.

It is on this note that we begin to explore how what happens in the classroom through interaction with teachers, fellow students, and material covered affects a student's ability to succeed. 
As Universal Design for Learning Framework attempts to create accessible learning spaces across both ability and culture (race, class, and ethnic identities), it is vital to examine how issues of identity affect the ability of a student to engage meaningfully with their education. In this section we begin to explore what the UDL framework may be missing in an attempt to ensure an accessible classroom across lines of identity.

\section{Invisible Intentions and other Biases}

In 1994 Anthony Greenwald wrote the first computer program to measure unconscious biases- a simple program that measured individuals' associations, in this case individuals' biases on flowers and insects- matching unpleasant and pleasant with flowers and insects. The program would determine, through a serious of fast moving exercises, if an individual had a bias that linked flowers with pleasant or the opposite. The test, soon to be named the Implicit Association Test (IAT), through simple sorting tasks was able to illustrate hidden biases that individuals may not have even known they had, and would have never explicitly owned up to (Banaji \& Greenwald, 2013). Experiencing the ease of the task of connecting pleasant words with images of flowers and the awkward discomfort of matching pleasant words with images of insects, it becomes possible to recognize our biases. Taking a test that determines that you have a strong bias of insects as unpleasant is hard to refute- it becomes harder when the tests take on more serious matters.

The race IAT followed soon after the insect IAT, simply replacing images of flowers and insects with images of African Americans and whites. Thus the test was able to measure an individual's attitude toward a racial group, a bias that most would not admit to or even know they had. The processes occur in the brain without conscious thinking, a connection of patterns to meaning. It is possible to connect the process of implicit bias to the recognition and affective networks of the brain outlined in UDL research. Individuals' recognize patterns and assign meaning from previous experiences, which is exactly what implicit bias addresses. 
The creators of the test themselves were surprised when they discovered their own implicit bias: their ease in associating White with pleasant over Black (Banaji \& Greenwald, 2013). However their surprise did not last long. As the test continues to be administered over the internet through their website Project Implicit as well as in their laboratory, they have found interesting results: 75 percent of those who take the Race IAT test have an automatic white preference (Banaji \& Greenwald, 2013, p. 47). Over time, the researchers created more IAT tests, including one that measured the black=harmful stereotype. This test prompted the user to link faces of black and white faces with images of harmful weapons and harmless objects. The results again are not surprising —over $70 \%$ of respondents foster an automatic black=harmful stereotype (Banjai \& Greenwald, 2013). However, when the data is broken into the race of the respondents, we see a shift. The white preference is largest with White and Asian testers, smaller with Hispanic responders, and smallest with African Americans (Banaji \& Greenwald, 2013, p. 105). The race of the responder affects their implicit biases. Further, Banaji and Greenwald assert that the result of automatic white preference is now regarded as an indicator for discriminatory behavior.

In 2009, 184 independent studies in which the Implicit Association Test was administered with an added measurement of discriminatory behavior were combined to be statistically analyzed. Using meta-analysis the researchers hoped to establish the validity of IAT tests in predicting discriminatory behavior. Greenwald, Poehlman, Uhlmann, \& Banaji (2009) found that for socially sensitive topics (such as race) the validity of the Implicit Association Test in predicting discriminatory behavior was relatively high. The IAT test reveals hidden biases at work in the subconscious mind that whether we are aware of it or not, affect our behavior.

For many individuals there is a distinct difference between knowing (a stereotype, for example) and endorsing the idea itself. In other words, the individuals who have taken the Race IAT test may have asserted they are not racist but, $75 \%$ of the test takers have an automatic white preference. This 
occurrence of having two mutually inconsistent ideas at the same time is defined by Greenwald and Banaji (2013) as dissociation (p. 58). Dissociation is a battle between the conscious and the unconscious, the reflective brain and the automatic brain. In terms of race, specifically how racism operates in the brain, it is not about endorsing stereotypes about black or brown folks. Greenwald and Banaji (2013) assert that "the distinction between knowing and endorsing is meaningless because there's no capacity for endorsing” (p. 98). Ultimately, it does not matter if an individual knows or endorses a negative belief about a race-- either way the bias is in the brain and affecting action. The question then becomes: how does this affect education? When Tony reflected on his first Race IAT test, he found himself asking - "Is this something that affects my behavior in relation to African Americans who I regularly encounter - especially students in my classes? Do I act as if I feel less positive toward them than toward White students?" (Banaji \& Greenwald, 2013, p. 45). What do these findings on automatic white preference mean in an education context in which the overwhelming percentage of teachers are white? It is on this note that we begin to explore how implicit bias shows up in classrooms.

I have already outlined that the results of an IAT test predict discriminatory behavior. However the discriminatory behavior does not predict overt racism but instead hidden biases that manifest themselves in our lived experiences (Banaji \& Greenwald, 2013). One major way this manifests itself is through in-group favoritism. If an individual is white and they have a Race IAT score of automatic white preference (a 75\% chance), this will affect how they operate around people of color, but more importantly and more drastically, how they operate around other whites. In-group favoritism, opposed to blatant exclusion of students of color, is a process of being racist through the act of being nice to those in one's in-group. It is widely regarded as being kind, offering favors, writing recommendations: things that on the surface seem to be positive practices. Yet the field of teaching is dominated by white teachers and white students in the higher tracks of education, so there are not enough people of color among the teachers and the students in advanced courses "to counter the propensity for in-group 
favoritism in the majority" (Banaji, Bazerman, \& Chugh, 2003, p. 60). There is not enough representation in classrooms to eradicated in-group favoritism. This reality connects back with the Universal Design for Learning principle of Multiple Means of Representation. UDL argues for diversity in representation in order for students to connect and become engaged with the material presented. It is through this rationale that we can connect how representation across lines of identity can affect students' engagement with their education. Research on IAT tests and in-group favoritism show that who is in a classroom affects the learning environment. Thus in order for classrooms to be equitable across racial lines, diverse representation is necessary.

It is important to clarify here that it is almost impossible to have every single student's race represented in the teachers and staff of the school they attend. However it is important to work in that direction in order to disrupt our current reality of the white female domination of the teaching field. As UDL proposes, the focus is on utilizing multiple means, in this case diversity in representation to promote engagement of the diverse student population. It is a disservice to students of color when they do not see themselves represented in their educators. Banaji \& Greenwald (2013) assert that those in a stereotyped groups still have implicit bias toward their own group, however-- it is lower in comparison to dominant groups (such as we saw with the black=harmful IAT test). Thus, I am not arguing that a mere implementation of a more diverse teaching staff will eradicate implicit bias. I am instead arguing that it is first and foremost a step in the right direction in terms of implicit bias, and it will also help in other areas, such as stereotype threat.

\section{Stereotype Threat}

As we talk about the necessity for multiple means of representation in student classrooms, it is helpful to think of how our own identities affect our work. Universal Design for Learning argues it is our brain networks, specifically recognition and affective networks, that enable us to perceive a 
situation, recognize patterns, and develop understanding. These networks affect what methods are beneficial for us in terms of learning but also how we come to understand our own identity in relation to others. Steele (2010) outlines what he refers to as identity contingencies: "the things you have to deal with in a situation because you have a given social identity" (p. 3). Social identities are anything from race, age, gender, sexuality, ability, and so on. Identities alter how we experience reality, even how we see reality: through our given lens. Further, identities carry with them stereotypes, some more harmful than others. For example: a black man in a hoodie at night as dangerous, Asian individuals as more intelligent, old people as technologically impaired, etc. These stereotypes affect how we behave on a street late at night, who we may ask for help from in a math class, and how we perceive our aging professors. When people with identities that carry stereotypes "were in a situation where those stereotypes could apply to them, they understood that one false move could cause them to be reduced to that stereotype, to be seen and treated in terms of it" (Steele, 2010, p. 7). This is called Stereotype Threat, a reality of identity contingencies that affect how individuals navigate situations.

Consider the stereotypes we know about students in a classroom. Who is smart and who is dumb? Who excels in math and who excels in the humanities? Steele and Aronson (1995) compiled four different tests around intellectual tests and stereotype threat in black participants. Equipped with the stereotype of black as dumb or scholastically incapable, the researchers conducted multiple studies that attempted to link stereotype threat to poor performance. They found just that: "Black participants expecting to take a difficult, ability-diagnostic test showed significantly greater cognitive activation of stereotypes about Blacks, greater cognitive activation of concerns about their ability, a greater tendency to avoid racially stereotypical preferences, a greater tendency to make advance excuses for their performance, and finally, a greater reluctance to have their racial identity linked to their performance even in the pedestrian way of recording it on their questionnaires" (Steele \& Aronson, p. 805). Stereotype threat affects individuals' ability to learn and succeed in their education. 
The association between blackness and violence has been already outlined. This too, plays a role in how teachers navigate their classrooms. Hugenberg and Bodenhausen (2003) wanted to study how prejudice (both implicit and explicit) affected the readiness to perceive anger in ambiguous black faces. Utilizing the IAT test, they found that higher levels of implicit (not explicit) prejudice correlated with a readiness to perceive anger on black faces while there was no such association with white faces. The ability to perceive a person as threatening based on first moments of interaction (as this was not a longitudinal study) solely based on the color of their skin points to the negative effects stereotypes foster. In the context of the school system, in which there is an overabundance of ambiguous faces, it is possible to see how this research plays out. As I have previously outlined, students of color are overrepresented in trouble-- rates of suspension, expulsion, and arrest. Black children are enmeshed into these stereotypes and must navigate them in the process of learning.

We must then begin to question how we come to understand stereotypes. For example, if all the white kids are in the advanced course, and the special education classes are overrun by black boys, what does that tell us about race and who is smart? It is through a process of observation that we begin to understand our surroundings. Stereotype threat plays a role in how students perceive themselves in academic settings and as illustrated above, affects how well they are able to perform. If we are to implement UDL into our classrooms effectively, we must look at what UDL is missing in creating a space for equal education to occur. UDL claims to create educational spaces that are accessible, engaging, and meaningful. Stereotype threat directly conflicts with these claims as it impedes access to an equitable education. Students learn from the patterns they see around them—such as more white students in advanced courses — and their affective and recognition networks process and store this information. Consequently, these networks affect how a student is able to engage, express, and understand information in the classroom. Stereotype threat affects learning but cannot be solved within the curriculum. In extension, the UDL principle of multiple means cannot be contained to the 
curriculum if UDL is to be successful. Thus, in order for UDL to assert itself as an equitable tool, it must take into consideration how stereotype threat and representation play a role in the classroom.

\section{In-Group Out-Group}

Categories shape how we see the world; we use them to group things together to establish differences and similarities. Self-categorization furthers this process by linking group belonging or identity with stereotyping (Hogg \& Abrams, 1988). It is along lines of difference (race, gender, class, ability) that bias, discrimination, and segregation are created and maintained. The field of identity development research has established that even with the application of arbitrary group boundaries, inter group bias can and will occur (Tajfel, 1970), Tajfel, Billing, Bundy, \& Flament (1971)). Casey \& Oleson's (2010) longitudinal research that randomly assigned fourth and fifth graders to different classrooms found inter-group bias that persisted for multiple weeks. As classrooms continue to be segregated across racial lines through the process of tracking, it is possible to establish that racially segregated classrooms foster an environment of racial bias. This again is a pattern that is recognized and then stored in students' brains (specifically, the affective and recognition networks store patterns) and in turn, plays a role in how we learn.

In terms of educators, stereotypes about race affect their ability to interact with students. Teachers are at a great risk of confirmation bias, the tendency to favor information that is consistent with their beliefs and ignore the contradictory information. For example, Bodenhausen \& Wyer (1985) found that once stereotypes are activated, an individual tends to focus on behaviors and tendencies that are consistent with the stereotype and ignore contradictory information. Murray (1996) documented that a student's race, class, and gender affect how they will be evaluated in the classroom. Stereotypes affect a teacher's ability to respond to students with a neutral or egalitarian standing.

Given conformation bias, even teachers who claim to be egalitarian educators "will remain 
unaware that their comfort and helpfulness in interactions with in-group members is not matched by similar levels of comfort and helpfulness toward out-group members" (Greenwald and Banaji, 2013, p. 160). Going back to Greenwald and Banaji's research into the Race IAT test, they found that of the more than 1.5 million White Americans who took the test, $40 \%$ who asserted themselves as an egalitarian received "automatic white preference" in the test (p. 158). The idea of an egalitarian educator must then be questioned. In a study conducted by Simpson \& Erikson (1983), the researchers documented that white teachers directed more nonverbal criticism toward black males than any other group. It is possible to see the effects of teachers highly critical of the educational performance of black boys and the reality that they dominate special education classrooms.

As UDL hopes to promote an accessible classroom based on individual learners' differences, it is beneficial to explore what differences affect learning. The many issues raised in this section (stereotype threat, implicit bias, and in-group/out-group discrimination) all rely on a complex notion of seeing an image (all white kids in advanced placement), seeing it repeatedly, assigning a meaning (black kids aren't as smart as white kids, and then expecting an outcome or norm from it (all black kids are less smart than all white kids). UDL outlines the networks in our brain that process information, the recognition and affective networks specifically address our recognition of patterns and assign meaning to them-- as noted throughout this piece, issues of identity are at work while learning. So if we are to create and endorse curriculum and programs to promote accessible learning we must begin to understand the lengths to which identity affects education and what we can do to change it.

\section{Counter-acting through Representation}

Throughout the previous sections I have explored such issues as stereotype threat, in-group outgroup discrimination, and implicit bias affect a learning environment. I want to specifically connect these issues with the UDL concept of multiple means-- that diversity in a learning environment makes 
the space more accessible. In other words, I want to highlight the ways in which UDL could or could not better make classrooms accessible across racial lines. I am arguing that representation (for example, black teachers for black students) will help counteract issues like implicit bias or stereotype threat. However, Maylor (2009) argues that positioning black teachers as role models for black student is a flawed mentality as it does not account for individual differences (if the teacher wants to be a role model, or if the students sees them as a role model). Although I grant the validity of Maylor's claim, I still maintain that representation (regardless of the assertion of teacher as a "role model") itself affects the learning environment. Several studies reflect my position. For example, Dasgupta \& Asgari (2004) researched how the presence of female professors in both a women's college and a co-ed college could affect women's implicit bias for their own in-group. This one year study hoped to explore if exposure to the stereotyped group would temporarily weaken implicit bias and if this was facilitated by the frequency of the encounter. The researchers found that automatic stereotyping was less likely to occur in spaces where the women had female professors. Further, those who have higher rates of exposure to female professors showed the lowest level of stereotypes. This research emphasizes the need for representation of stereotyped identities in leadership positions in order to reduce both implicit bias and in-group/out-group discrimination. The importance of diverse representations plays right into the foundations of UDL. The Universal Design for Learning framework positions the need for multiple means in order to promote accessibility and engagement for the individual learner. In this context, multiple means can be expanded to include the identities of who is in the room in order to make a classroom accessible.

Devine, Forscher, Austin, \& Cox (2012), using the Race IAT test, developed an intervention strategy in hopes of reducing implicit racial bias and sustaining reduction over the long-term. This 12week study found that all individuals had a reduction in the implicit racial bias compared to those in the control group who received no intervention. People who were concerned about discrimination and 
social inequality showed the greatest reductions in bias. The intervention proposed five different strategies for the subjects to utilize in order to counter their implicit bias: stereotype replacement, counter-stereotypic imaging, individuating, perspective taking, and contact with out-group members (Devine, Forscher, Austin, \& Cox, 2012, p. 1270). Counter-stereotypic imaging and contact both rely on the importance of representation for the reduction of implicit-bias. Thus, it is possible to argue that increased representation of marginalized identities plays a role in reducing the implicit bias and its affects.

In addition, Dee (2004) found that math and science scores were higher for both white and black students if the teacher was the same race as the student. These studies show the importance that representation plays in the reduction of the harmful effects of implicit bias and academic opportunity gaps. These findings indicate that there is a link between who is represented in the classroom and academic achievement. As diversity in representation is a principle of UDL, it is possible to extend diversity of representation to include the representation of diverse racial identities.

Considering the effects of stereotype threat on academic achievement that I have discussed above, Steele (2010) points to positive affirmations and sharing student narratives as a normalizing practice as interventions that reduce stereotype threat. Although it is unclear how an expanded understanding of UDL would be beneficial in these two areas of intervention, there are others that do incorporate UDL principles. Steele et al.'s 2008 study (as cited in Steel, 2010) found specific tactics that helped create a space of positive identity for the students, such as: "use of their diversity as a classroom resource rather than following a strict strategy of colorblindness; teacher skill, warmth, and availability." (p. 180). In other words, recent evidence indicates the need for promoting diverse representations (of the teachers, students, and materials) in the classroom instead of ignoring it in order to reduce stereotype threat. The depth of the student-teacher relationship, as I have previously discussed, is directly related to who is in the classroom. In order for stereotype threat to be lessened, we 
need positive teacher-student dynamics. As teacher-student dynamics are directly connected to ingroup/out-group biases, it then becomes important to acknowledge that identity affects the relationship. Thus, diverse representations matter in order to create and maintain positive spaces for learning for diverse students.

The Universal Design for Learning framework is not an all-inclusive tool as it does not account for how the identities in the classroom affect the accessibility of the information. As I have discussed, representation plays a meaningful role in the facilitation of education. As UDL principles rely heavily on the importance of diverse representations and multiple means but do not address identity; it is possible to argue that UDL must be expanded if it is to be an effective tool.

Universal Design for Learning is a framework that positions itself as a tool to make classrooms accessible across lines of disability and diversity through neuroscience research. However, it is possible to see through issues raised by stereotype threat, confirmation bias, and the Race IAT test that our brains are working in racialized manner and that in turn, affects the accessibility of education. UDL grounds itself in the principle of multiple means and that extends past the curriculum into the representation of racial identities in the classroom. Thus, for UDL to be effective, public schools need to take into account issues like stereotype threat in relation to ensuring multiple means of engagement, representation, and action.

\section{Conclusion}

Through this piece I aim to argue that Universal Design for Learning is a beneficial tool to be used in the changing classrooms of the United States. As classroom demographics continue to shift, the public school system is seeking out solutions to improve academic achievement, such as the Common Core. The Universal Design for Learning framework is one such proposed solution, although it is a recent development-- just beginning to be implemented and researched. UDL has been argued as a tool 
to ensure classrooms are accessible across lines of ability status and identity. The three principles of providing multiple means of representation, action, and engagement facilitate accessible classrooms. However, I argue that accessibility across lines of identity difference is a problem that extends beyond curriculum. My contribution is to synthesize research from the fields of sociology, education, and neuroscience and aruge that the framework of multiple means under UDL must be expanded to include the students' identities in the classroom in order to reduce opportunity gaps.

As UDL relies heavily on the assertion that there must be multiple means of representation, I have argued that that principle must be expanded to include representation of different identities- in particular, race- in the classroom. Representation has an effect on a student's educational success. As UDL relies on neuroscience based research, I aimed to draw from brain based research on how an individuals' race affects their ability to access education. Through the discussion on implicit bias, stereotype threat, and confirmation bias I established that representation affects learning. Further, the research on how to lower implicit bias points to the importance of representation of marginalized groups. These findings connect back to the UDL principle of multiple means- we need diverse representation in order to facilitate accessibility in our public education classrooms. This discussion contributes to the growing research in the field of UDL. It specifically begins the conversation on what UDL is overlooking in order to create a universal framework. Ultimately, I am aiming to advance the conversation already happening with UDL researchers in order to begin to better promote diversity in a universal framework.

There are many limitations to my work. Due to various constraints, my research centered itself around issues related to race. There are many more intersecting identities that need to be taken into consideration. Further, much of the research I used sets up a black-white dynamic and did not address other races or ethnicities. Anti-black racism in this country operates in a different manner than other races and it is important that future research explores that. Further, UDL has been implemented in 
many schools across the nation but there has been no direct study into how representation of who is in the room works in a functioning UDL classroom. That level of study would be beneficial in order to further my assertion. After more research has been conducted, it would be possible to begin to construct principles and policies that would expand UDL to include identity officially. There is much room for further study along the intersection of UDL and representation of identities. Further, I focused on the importance of the identities of the teacher--student relationship in the context of UDL implementation. More research is needed to examine the role that identities play in students' relationships with one another and student's relationship with class materials (textbooks, curriculum) in the context of a UDL learning environment.

I have focused on the connection between UDL and racial identity; however it is important to note what UDL may fail to address. It is unclear how effective UDL will be in relation to dealing with inequality along lines of social class. There is recent evidence to suggest that by 18 months there are already language learning gaps present based on social economic status (Fernald, Marchman, \& Weisleder, 2013). These inequalities by social class mean that lower-income students often enter into the public education system already disadvantaged. Future research on UDL could also explore the extent to which having diverse socioeconomic statuses represented by teachers and in curricula could help students from lower-income backgrounds better access their education.

Universal Design for Learning continues to be a promising tool for ensuring accessibility in the classroom. Although I argue first and foremost for the implementation of UDL, I have proposed a critique of the framework. In order for UDL to be truly effective, it must be expanded. I have argued for an expanded definition of the UDL principle of multiple means, proposing that the principle be expanded to include multiple identities in the classroom. As I have explored, representation affects learning and thus in order for Universal Design for Learning to be an effective tool it must be expanded to factor in how identities that are present in the room (or not) make education inaccessible. In 
synthesizing the UDL framework and identity development research we are able to recognize how identity affects learning and thus affects the effectiveness of Universal Design for Learning. My research is necessary to the field of Universal Design for Learning as it begins a critical examination of the limitations of UDL and how it could be improved. The field of UDL research is lacking critiques of the framework and thus my research begins a necessary discussion that will better enable UDL to ensure its claims of accessibility. It is through the process of examining how representation works in a classroom that we can position diversity in the center of Universal Design for Learning. 


\section{References}

Advancement Project (2005). Education on Lockdown: The Schoolhouse To Jailhouse Track. Retrieved from: http://www.advancementproject.org/resources/entry/education-on-lockdown-theschoolhouse-to-jailhouse-track

Alaya, E., Brace, H. J., \& Stahl, S. (2012). Preparing Teachers to Implement Universal Design for Learning. In T. E. Hall, A. Meyer, \& D. H. Rose (Ed.), Universal Design for Learning in the Classroom: Practical Applications. (pp. 135-152) New York, London: The Guildford Press

Archer, D. N. (December 15, 2009). Introduction: Challenging the School-to-Prison Pipeline. New York Law School Law Review, 54, 4.)

Banaji, M. R., \& Greenwald, A. G. (2013). Blindspot: Hidden biases of good people. New York: Delacorte Press.

Banaji, M. R., Bazerman, M. H., \& Chugh, D. (January 01, 2003). How (un) ethical are you?. Harvard Business Review, 81, 12, 56-64.

Barton, P. E. \& Coley, R. J.. (2009). Parsing the achievement gap II. Princeton, NJ: Policy Information Center, Educational Testing Service.

Bertin, Mark. (2014, January 22). When Will We Ever Learn: Dissecting the Common Core State Standards with Dr. Louisa Moats. Retrieved from: http://www.huffingtonpost.com/mark-bertinmd/when-will-we-ever-learn_b_4588033.html

Blizzard, D., \& Foster, S. (January 01, 2007). Feminist Pedagogy and Universal Design in a Deaf and Hearing World: Linking Cultures through Artifacts and Understanding. Feminist Teacher: $a$ Journal of the Practices, Theories, and Scholarship of Feminist Teaching, 17, 3, 225-236. 
Bodenhausen, G. V., \& Wyer, R. S. J. (January 01, 1985). Effects of stereotypes on decision making and information-processing strategies. Journal of Personality and Social Psychology, 48, 2, 267-82.

Boger, J. C., \& Orfield, G. (2005). School Resegregation: Must the South turn back?. Chapel Hill: University of North Carolina Press.

Bowe, F. (2000). Universal design in education: Teaching nontraditional students. Westport, Conn: Bergin \& Garvey.

CAST (2010, March) Recommendations for the Common Core Standards. In Statements. Retrieved from: http://www.cast.org/library/statements/standards/index.html

CAST (2011). Universal Design for Learning Guidelines version 2.0. Wakefield, MA: Author.

Chita-Tegmark, M.., Gravel, J. W., Serpa, M. D. L. B., Domings, Y., \& Rose, D. H. (2011/12). Using the Universal Design for Learning Framework to Support Culturally Diverse Learners. Journal of Education, 192(1), p. 17-22.

Coyne, P., Ganley, P., Hall, T., Meo, G., Murray, E., \& Gordon, D. (2009). Applying Universal Design for Learning in the Classroom. In D.H. Rose \& A. Meyer (Ed.), A Practical Reader in Universal Design for Learning. (pp. 1-14) Cambridge, Massachusetts: Harvard Education Press.

Dasgupta, N., \& Asgari, S. (2004). Seeing is Believing: Exposure to Counterstereotypic Women Leaders And Its Effect On The Malleability Of Automatic Gender Stereotyping. Journal of Experimental Social Psychology, 40, 5, 642-658.

Dee, T. S. (2004). Teachers, Race, and Student Achievement in a Randomized Experiment. Review of Economics and Statistics, 86, 1, 195-210. 
Devine, P. G., Forscher, P. S., Austin, A. J., \& Cox, W. T. L. (2012). Long-Term Reduction In Implicit Race Bias: A Prejudice Habit-Breaking Intervention. Journal of Experimental Social Psychology, 48, 6, 1267-1278.

Feistritzer, E. (2011). Profile of teachers in the U.S. Retrieved February, 13, 2014. from http://www.ncei.com/Profile_Teachers_US_2011.pdf

Fernald, A., Marchman, V. A., \& Weisleder, A. (2013). SES differences in language processing skill and vocabulary are evident at 18 months. Developmental Science, 16, 2, 234-248.

Files, J. S., Casey, C. M., \& Oleson, K. C. (June 01, 2010). Intergroup bias in children: Development and persistence. European Journal of Social Psychology, 40, 4.)

Flores, G. M. (January 01, 2011). Racialized Tokens: Latina Teachers Negotiating, Surviving and Thriving in a White Woman's Profession. Qualitative Sociology, 34, 2, 313-335.

Freeman, C.E., Scafidi, B., \& Sjoquist, D. (2005) Racial Segregation in Georgia Public Schools, 19942001: Trends, Causes, and Impact on Teacher Quality. In J.C. Boger and G. Orfield (Ed.), School Resegregation: Must the South Turn Back? Chapel Hill and London: University of North Carolina Press.

Gostin, L. O., Vanchieri, C., Pope, A. M. P., Institute of Medicine (U.S.)., \& Institute of Medicine (U.S.). (2007). Ethical considerations for research involving prisoners. Washington, D.C: National Academies Press.

Greenwald, A. G., Poehlman, T. A., Uhlmann, E. L., \& Banaji, M. R. (January 01, 2009). Understanding and using the Implicit Association Test: III. Meta-analysis of predictive validity. Journal of Personality and Social Psychology, 97, 1, 17-41.

Higher Education Education Act. (2008) Public Law 110-315. Washington, DC: U.S. Government 
Printing Office.

Hogg, M. A., \& Abrams, D. (1988). Social identifications: A social psychology of intergroup relations and group processes. London: Routledge.

Hugenberg, K., \& Bodenhausen, G. V. (November 01, 2003). Facing Prejudice: Implicit Prejudice and the Perception of Facial Threat. Psychological Science, 14, 6, 640-643.

IDEA Data. (2011). Educational Environments 2011. In Historical State-Level IDEA Data Files. Retrieved from: http://tadnet.public.tadnet.org/pages/712

Kortering, L. J., McClannon, T. W., \& Braziel, P. M. (January 01, 2008). Universal Design for Learning: A Look at What Algebra and Biology Students with and without High Incidence Conditions Are Saying. Remedial and Special Education, 29, 6, 352-363.

Lopez, G. R. (September 01, 2001). The Value of Hard Work: Lessons on Parent Involvement from an (Im)migrant Household. Harvard Educational Review, 71, 3.)

Maylor, U. (2009). 'They do not relate to Black people like us': Black teachers as role models for Black pupils. Journal of Education Policy, 24, 1, 1-21.

Mickelson, R.A. (2005) The Incomplete Desegregation of the Charlotte-Mecklenburg Schools and Its Consequences, 1971-2004. In J. C. Boger \& G. Orfield (Ed). In School resegregation: Must the South turn back? (pp. 87-110) Chapel Hill: University of North Carolina Press.

Milner, H. R. (2010). Start where you are, but don't stay there: Understanding diversity, opportunity gaps, and teaching in today's classrooms. Cambridge, Mass: Harvard Education Press.

Murray, C. B. (February 01, 1996). Estimating Achievement Performance: A Confirmation Bias. Journal of Black Psychology, 22, 1, 67-85. 
National Center for Children in Poverty. Addy, S., Egelhardt, W., \& Skiner, C. (2013, January). Basic Facts about Low-income Children. In Publications. Retrieved from: http://www.nccp.org/publications/pub_1074.html

National Center for Education Statistics (NCES). (2013). The Condition of Education 2013. Retrieved from: http://nces.ed.gov/programs/coe/current_tables.asp

Orfield, G., Eaton, S. E., \& Harvard Project on School Desegregation. (1996). Dismantling desegregation: The quiet reversal of Brown v. Board of Education. New York: New Press.

Ostroff, C. (1992, December). The relationship between satisfaction, attitudes, and performance: An organizational level analysis. Journal of Applied Psychology, 77, 6, 963-974.

Peters, W.,(Producer, Director) (1971). The Eye of the storm. New York?: ABC Media Concepts.

Rose, D. H., \& Meyer, A. (2002). Teaching every student in the Digital Age: Universal design for learning. Alexandria, Va: Association for Supervision and Curriculum Development.

Rose, D. H., Gravel, J. W., \& Domings, Y. (2012) Universal Design for Learning “Unplugged”: Applications in Low-Tech Settings. In T. E. Hall, A. Meyer, \& D. H. Rose (Ed.), Universal Design for Learning in the Classroom: Practical Applications. (pp. 120-134) New York, London: The Guildford Press

Rothstein, L. F. (2000). Special Education Law. New York: Longman.

Schildroth, A. N., \& Hotto, S. A. (1994) Deaf Students and Full Inclusion: Who Wants to be Excluded? In O. Cohen and R. C. Johnson (Ed.), Implications and Complications for Deaf Students of the Full Inclusion Movement (pp 7-30)Washinton, D.C.: Gallaudet Research Institute

Schott Foundation for Public Education. (2012). The Urgency of Now. Retrieved from: 
http://www.schottfoundation.org/urgency-of-now.pdf

Simmons, R. G., \& Blyth, D. A. (1987). Moving into adolescence: The impact of pubertal change and school context. New York: A. de Gruyter.

Simpson, A. W., \& Erickson, M. T. (January 01, 1983). Teachers' Verbal and Nonverbal Communication Patterns as a Function of Teacher Race, Student Gender, and Student Race. American Educational Research Journal, 20, 2, 183-198.

Skiba, Russell. (2004, summer).Zero Tolerance: The Assumptions and the Facts. Center for Evaluation \& Education Policy: Education Policy Briefs, 2, 1, 1-8. Retrieved from: http://files.eric.ed.gov/fulltext/ED488918.pdf

Skiba, R. J., Horner, R. H., Chung, C.-G., Rausch, M. K., May, S. L., \& Tobin, T. (2011). Race Is Not Neutral: A National Investigation of African American and Latino Disproportionality in School Discipline. School Psychology Review, 40, 1, 85-107.

Smith, F. G. (September 01, 2012). Analyzing a College Course That Adheres to the Universal Design for Learning (UDL) Framework. Journal of the Scholarship of Teaching and Learning, 12, 3, $31-61$.

Sopko, K. M. (2009). Universal Design for Learning: Policy Changes and Recommendations. In D. T. Gordon, J. W. Gravel, \& L. A. Schifter (Ed. ), A Policy Reader in Universal Design for Learning. (pp. 93-108) Cambridge, Massachusetts: Harvard Education Press

Spooner, F., Baker, J. N., Harris, A. A., Ahlgrim-Delzell, L., \& Browder, D. M. (March 01, 2007). Effects of Training in Universal Design for Learning on Lesson Plan Development.Remedial and Special Education, 28, 2, 108-116.

Steele, C. (2010). Whistling Vivaldi: And other clues to how stereotypes affect us. New York: W.W. 


\section{Norton \& Company.}

Steele, C. M., \& Aronson, J. (January 01, 1995). Stereotype Threat and the Intellectual Test Performance of African Americans. Journal of Personality and Social Psychology,69, 5, 797.

Taylor, L. S., \& Whittaker, C. R. (2003). Bridging multiple worlds: Case studies of diverse educational communities. Boston: Allyn and Bacon.

Tajfel, H. (November 01, 1970). Experiments in Intergroup Discrimination. Scientific American, 223, 5, 96-102.

Tajfel, H., Billig, M. G., Bundy, R. P., \& Flament, C. (April 01, 1971). Social categorization and intergroup behaviour. European Journal of Social Psychology, 1, 2, 149-178.

Tatum, B. D. (2007). Can we talk about race?: And other conversations in an era of school resegregation. Boston, Mass: Beacon Press.

U.S. Bureau of Labor Statistics. (2013, February). Women in the Labor Force: A Databook. Retrieved from: http://www.bls.gov/cps/wlf-databook-2012.pdf

U.S. Bureau of Labor Satistics. (2014) Table A-16. Persons not in the labor force and multiple jobholders by sex, not seasonally adjusted. In Economic News Release. Retrieved from: http://www.bls.gov/news.release/empsit.t16.htm

United States Census Bureau. (2012, May 17). Most Children Younger Than Age 1 are Minorities, Census Bureau Reports. In Releases. Retrieved from http://www.census.gov/newsroom/releases/ archives/population/cb12-90.html

U.S. Department of Education, National Center for Education Statistics, Schools and Staffing Survey (SASS), "Public School Teacher, BIE School Teacher, and Private School Teacher Data Files," 
2007-08.

Wilson, W. J. (1987). The truly disadvantaged: The inner city, the underclass, and public policy. Chicago: University of Chicago Press. 